\title{
CONFLITOS FUNDIÁRIOS URBANOS NO PODER JUDICIÁRIO: ESTRATÉGIAS DISCURSIVAS NO FUNDAMENTO DAS DECISÕES
}

\author{
URBAN LAND CONFLITCTS IN LAW POWER: DISCURSIVES STRATEGIES MOBILIZED \\ IN THE BASIS OF THE DECISIONS
}

\section{Giovanna Bonilha Milano ${ }^{1}$}

\section{Resumo}

A disputa pelo acesso à terra pela moradia é geradora de enfrentamentos entre interesses de proprietários e não proprietários, os quais frequentemente são traduzidos à esfera institucional para intervenção jurisdicional. Sob tal premissa, a hipótese da pesquisa consiste na afirmação de que atuação do Poder Judiciário nos conflitos fundiários urbanos integra os elementos de (re)produção da segregação socioespacial nas cidades brasileiras. A investigação fundou-se na realização de pesquisa quantitativa e qualitativa com a análise das decisões sobre conflitos fundiários urbanos coletivos, proferidas em Tribunais de Justiça das cinco regiões brasileiras, no período entre 2014 e 2015. Incorporou-se, ainda, o acervo jurisprudencial dos Tribunais Superiores sobre a temática, produzido no período entre 2002 a 2015. Os resultados qualitativos são apresentados neste artigo por meio da sistematização das estratégias discursivas mobilizadas no fundamento das decisões que autorizam as remoções forçadas da população nos espaços informais de moradia.

Palavras-chave: Conflitos Fundiários Urbanos; Direito à Moradia; Poder Judiciário; Decisões Jurisdicionais.

\begin{abstract}
The dispute over access to land for housing generates conflicts between interests of owners and nonowners, which are often translated into the institutional sphere for jurisdictional intervention. Under such a premise, the research hypothesis consists of the assertion that the Judiciary's performance in urban land conflicts integrates the elements of (re) production of socio-spatial segregation in Brazilian cities. The investigation was based on the accomplishment of quantitative and qualitative research with the analysis of decisions on collective urban land conflicts, handed down in Courts of Justice of the five Brazilian regions, in the period between 2014 and 2015. The jurisprudence of the Superior Courts on the subject, produced in the period between 2002 and 2015, were also included. The qualitative results are presented in this article through the systematization of the discursive strategies mobilized in the basis of the decisions that authorize the forced removals of the population in the informal spaces of dwelling.
\end{abstract}

Keywords: Urban Land Conflicts; Right to Housing; Law Power; Court Decisions.

\footnotetext{
${ }^{1}$ Doutora em Direito das Relações Sociais pela Universidade Federal do Paraná. Professora dos cursos de graduação e pós-graduação da Universidade Positivo. Pesquisadora do Grupo de Pesquisa "Direitos Humanos, Democracia e Conflitos Sociais" (UFPR). E-mail: giovanna.milano@gmail.com
} 


\section{INTRODUÇÃO}

A segregação socioespacial corresponde a elemento estruturante das cidades brasileiras, em fenômeno determinado por variáveis econômicas, sociais, políticas e também jurídicas. A análise dos processos de remoções forçadas, motivou a realização de pesquisa empírica com o objetivo de se compreender mais detalhadamente a existência de certa regularidade nas decisões do Poder Judiciário, sobre conflitos fundiários urbanos. Em outras palavras, sendo a segregação socioespacial um dado intrínseco da constituição das cidades brasileiras, com a participação evidenciada de atores múltiplos - estatais e não estatais quais as peculiaridades de seu processo de tradução nos afazeres no Judiciário? Em que medida tal atuação se compara ou se difere à participação dos demais agentes políticos e institucionais que compõem o mosaico do Estado Democrático de Direito? Qual a distância ou a proximidade entre as situações processuais e as dinâmicas conflitivas espaciais que Ihe são subjacentes?

De saída, o campo do Poder Judiciário apresentou-se como um terreno bastante espinhoso para investigação. A dificuldade do acesso às fontes (as decisões); a terminologia em descompasso com a literatura dos estudos urbanos; a incerteza dos dados e o ambiente bibliográfico rarefeito colocaram-se como obstáculos permanentes. Ao mesmo tempo, entretanto, colocavam-se como indícios de que a pesquisa sobre as decisões era um caminho adequado e necessário e que, os silêncios nos falavam sobre o desconhecimento acerca de um poder democrático pouco conhecido, pouco questionado, mas bastante potente.

Ao mesmo tempo, a ausência de informações em âmbito nacional que dessem conta da ocorrência de conflitos fundiários urbanos nos apresentava o questionamento sobre o universo territorial da pesquisa e sua correlação com a estrutura do Poder Judiciário. Trabalhamos, então, com as informações disponíveis. A existência de um mapeamento dos aglomerados subnormais pelo IBGE foi tomada como ponto de partida, a partir da dedução de que nos locais em que se identificam irregularidades fundiárias tem-se potencialmente situações de conflito fundiário. A concentração dos aglomerados na região sudeste - especialmente Rio de Janeiro, São Paulo e Minas Gerais - dificultavam a intenção de se empreender uma pesquisa que pudesse colher elementos no âmbito nacional. Firmou-se, portanto, o critério por meio do qual seriam selecionadas - em cada região - a unidade federativa que possuísse maior número de aglomerados. E assim foram definidos: São Paulo, Pará, Pernambuco, Rio Grande do Sul e Distrito Federal. 
Estabelecidos os critérios territoriais, foi necessário pensar desde a organização do judiciário para definir a instância a ser analisada -neste caso, o 2o grau de jurisdição - e a competência adequada - neste caso a Justiça Estadual. A análise foi realizada nas decisões proferidas entre 2014 e 2015. Agregou-se, ainda, os Tribunais Superiores - STJ e STF - pelo papel constitucional que cumprem no alinhamento das decisões do Poder Judiciário e para estes tribunais considerou-se o período entre 2002 e 2015. As decisões coletadas neste âmbito, entretanto, foram utilizadas exclusivamente na etapa qualitativa da pesquisa sob pena de ocorrer conflito entre bases de dados construídas sob períodos distintos.

Utilizou-se o mesmo método para análise de todas as decisões. Fez-se uma seleção inicial com a leitura das ementas e a verificação da adequação ou não aos parâmetros estabelecidos a partir da conceituação da noção de conflitos fundiários urbanos ${ }^{2}$. Analisaramse, nesta etapa, 49.844 ementas nos Tribunais Estaduais e 139.231 ementas nos Tribunais Superiores.Deste montante, foram selecionadas 311 decisões cujo inteiro teor passou a uma análise mais apurada e cujos elementos, finalmente, foram tabulados conforme critérios estabelecidos no instrumento de coleta.

Um primeiro esforço de captura dos indicadores disse respeito aos elementos estruturantes dos processos. Características gerais dos sujeitos, dos imóveis em disputa e das modalidades de ação utilizadas para judicialização dos conflitos. Traçamos, ao fim um perfil, que se não representa a totalidade dos conflitos fundiários urbanos no Brasil, é bastante forte em relação às informações que puderam ser extraídas a partir das fontes analisadas. Podemos afirmar que as situações de despossessão são operadas especialmente por meio de ações possessórias (84\%), e particularmente de ações de reintegração de posse $(97 \%)$. Os autores dos recursos correspondem majoritariamente a coletividades de moradores, sem identificação individualizada de cada um dos interessados e registro pouco expressivo de atores coletivos que os identifiquem de maneira unificada (como movimentos sociais urbanos, cooperativas, ong's, etc.). Além disso $64 \%$ dos recorrentes correspondem aos réus nas ações originárias, motivo pelo qual os pedidos recursais envolvem principalmente a tentativa de reforma das decisões do juízo originário que autorizaram o despejo.

\footnotetext{
${ }^{2}$ A definição de conflito fundiário urbano adotada no trabalho corresponde aos termos da Resolução Recomendada n.87/2009, elaborada pelo Conselho Nacional das Cidades, qual seja: "disputa pela posse ou propriedade de imóvel urbano, bem como impacto de empreendimentos públicos e privados, envolvendo famílias de baixa renda ou grupos sociais vulneráveis que necessitem ou demandem a proteção do Estado na garantia do direito humano à moradia e à cidade."
} 
Em relação aos recorridos, são majoritariamente pessoas físicas individuais, embora se destaque a presença de pessoas jurídicas (e de pessoas jurídicas de direito público, especialmente municipalidades). O Poder público participa, portanto, intensamente das situações de despossessão jurisdicionalizada. A maior parte dos imóveis em disputa são privados, embora a diferença numérica seja praticamente insignificante, o que reforça esta conclusão. O Ministério Público e a Defensoria Pública apareceram de maneira pouco expressiva tanto no polo ativo quanto no polo passivo.

Além disso, identificou-se uma expressiva concessão de decisões liminares que autorizavam o despejo sem sequer realizar a oitiva dos moradores. Sugestiva construção jurídica edificada sob o brocado "inaudita altera parte", ou seja, sem que seja ouvida a outra parte e que significa com precisão qual o lugar do não-proprietário na leitura jurisdicional destes conflitos. O curioso é que a manobra jurídica seletiva se esconde justamente neste movimento paradoxal: Em que pese nas ações possessórias não se possa discutir a dominialidade da área, é por meio do registro formal do título de propriedade que as liminares são concedidas. Criando-se, portanto, uma prova impossível aos ocupantes que não são ouvidos ou, que, ao se manifestarem no processo não encontram eco na comprovação da inadequação fática e jurídica do exercício proprietário, por meio da indicação do não cumprimento da função social da propriedade. Seletividade que aparece em caixa alta, com o subsídio no rito processual possessório que assim o autoriza.

Não por outra razão, o fundamento das decisões fundou-se majoritariamente na "comprovação suficiente dos requisitos para reintegração de posse", com base no artigo correspondente do Código de Processo Civil. A legislação, aliás, foi a fonte do direito mais recorrentemente mobilizada como fundamento das decisões. Não qualquer legislação, mas especialmente o Código Civil e o Código de Processo Civil. Legislações outras, como o Estatuto da Cidade, e leis urbanísticas municipais tiveram aparição pouco expressiva. Surpreendeu-nos, entretanto, o baixo recurso ao texto constitucional - que quando citado, em regra não impactou no resultado da disputa - e aos diplomas internacionais de direitos humanos que serviram de subsídio para fundamentar uma única decisão.

Neste quadro interpretativo forjado em um formalismo gritante, parecia-nos relevante entender como se davam as estratégias argumentativas que possibilitavam suspender o considerável arcabouço legislativo existente que protege o direito à moradia no Brasil. Passamos a sistematização das estratégias argumentativas e as agrupamos em quatro argumentos fundamentais que serão apresentados a seguir. 


\section{ESTRATÉGIAS DISCURSIVAS E DIREITO À MORADIA NAS DECISÕES JURISDICIONAIS}

Se é verdade que os conflitos fundiários urbanos são julgados por um rito possessório que confere pouca ou nenhuma participação processual efetiva aos não proprietários, também é preciso dizer que estes, ao se manifestarem nos processos, sobretudo na fase recursal, provocam o Judiciário com a apresentação de direitos e princípios violados nas remoções forçadas. A observância do direito à moradia, o respeito ao princípio da dignidade da pessoa humana e a necessária vinculação do exercício proprietário à função social que the é respectiva, são argumentos reiterados pelas partes despejadas e seus representantes.

Um caso pode ser elucidativo para apontar as reflexões que se almeja desenvolver. Em agravo de instrumento decidido no ano de 2014, a Defensoria Pública do Estado do Rio Grande do Sul buscava a reforma de decisão que autorizou a reintegração de posse em área localizada no município de Porto Alegre. Nessa área, de propriedade de empresa particular, existia ocupação consolidada em que moravam mais de 400 famílias, há anos, e cujo despejo importaria em significativa repercussão social. Nos autos, os elementos da situação fática subjacente ao conflito processual foram apontados pela defesa dos réus que destacou, ainda, as violações constitucionais que seriam deflagradas em caso de autorização judicial do despejo.

Na narrativa apresentada pelo relatório da decisão, a Defensoria Pública:

Aduziu que a situação envolve mais de 400 famílias em situação de vulnerabilidade, havendo clara colidência entre normas constitucionais. Destacou a dignidade da pessoa humana, direito a saúde, segurança, moradia. Ponderou que há conflito com o direito de propriedade também garantido pela Constituição Federal. Asseverou que deve haver uma maior reflexão quanto à afronta a direitos mínimos de subsistência e dignidade. Destacou que a área está sem destinação econômica há mais de 20 anos e a posse das famílias ocupantes está consolidada. Alegou que primeiramente deve ser solucionado o alojamento das famílias, lembrando de situação similar ocorrida em São Paulo, na qual famílias foram desalojadas e um ano depois a área ainda só tem mato, cercas e vigias. $^{3}$ (SÃO PAULO, Apelação no 0001033-06.2004.8.26.0642, 2015, p.7)

\footnotetext{
${ }^{3}$ Note-se que a argumentação da Defensoria Pública faz menção direta ao caso de despejo realizado na comunidade do Pinheirinho, em São José dos Campos. Tamanha a repercussão do ocorrido naquela oportunidade que várias decisões e manifestações de réus utilizam este caso como situação exemplar que deve ser evitada na atuação jurisdicional. Os sentidos, entretanto, nem sempre são unívocos. Os moradores relembram o Pinheirinho como forma de demonstrar ao juízo a potencialidade de violação de direitos em decorrência das remoções forçadas. Na fala dos magistrados, entretanto, o Pinheirinho foi lembrado como uma situação que se tornou extremamente gravosa em função da demora para dar uma solução definitiva à reintegração. Nesse sentido, por exemplo, a menção realizada por magistrado em recurso sobre reintegração de posse: "Tal constatação revela que a protelação de decisões pode recrudescer o litígio e tomar dimensões em que a solução é de difícil execução, a exemplo do conflito fundiário na comunidade de Pinheirinho, em São José dos Campos. A presidência deste Tribunal de
} 
Especialmente em sede recursal, âmbito jurisdicional objeto de análise nesta tese, os moradores sob ameaça de remoção apontam suas razões e justificam sua permanência com a demonstração de vulnerabilidades concretas que integram a existência nas ocupações. Mas, também, com o recurso à gramática dos direitos - especialmente dos direitos humanos e constitucionais - que integram formalmente o ordenamento jurídico nacional, possuem força normativa, e, portanto, devem ser considerados como matéria de defesa na ponderação dos interesses em conflito no caso concreto. Bem é verdade que dificilmente a apresentação destes argumentos pelos réus reverbera em resultados de manutenção do direito à moradia que lhes seja favorável. Ainda assim, para que o juiz possa se desembaraçar dos argumentos apresentados pelas famílias despejadas, é preciso que ele também se utilize de recursos técnicos, jurídicos e, não raro, extrajurídicos que balizem a escolha da melhor decisão. Isso demanda a formulação de um raciocínio que equacione os direitos em conflito, apontados pelas partes, posicionando-os diante da interpretação sistêmica que é dada ao magistrado realizar.

Na situação da reintegração de posse no município de Porto Alegre, que citamos acima, o juiz deferiu sua execução dialogando com as ponderações da defesa, sob a seguinte chaveargumentativa:

Não se pode tolerar, com a invocação do problema social a violação às regras que tutelam o direito de propriedade e o direito de posse, com a intenção deliberada de invasão. Os problemas sociais devem ser solucionados, com certeza, nas nunca desta maneira, com invasão. Assim agindo, caracterizaram o seu comportamento como contrário ao ordenamento jurídico. Cometeram esbulho possessório, com demarcação e construções sobre o imóvel de propriedade e posse da empresa requerente. Não podem, pois, merecer qualquer proteção legal. (RIO GRANDE DO SUL, Agravo Interno n 70062200100, 2014, p. 5).

Como se percebe, os direitos aventados pelos sujeitos destinatários do despejo são interpretados e dimensionados pelo magistrado, sob a influência de variáveis que perpassam o juízo moral e a avaliação jurídica dos juízes diante das ocupações coletivas e dos "invasores". Mas também, refletem a compreensão dos julgadores acerca da densidade normativa atribuída ao direito à moradia; das funções institucionais no que tange à separação dos poderes e, especialmente, à responsabilidade do Poder Judiciário no quadro de segregação urbana das cidades brasileiras.

Assim, nas trilhas do que defende Oscar Correas (1986, p. 12), há um campo rico de compreensão do direito como discurso jurídico, não exclusivamente afeto às normas, mas

Justiça, inclusive, sensível ao argumento de que conflitos fundiários devem ser rapidamente solucionados, criou grupo especialmente designado para mediar as reintegrações mais ruidosas".(SÃO PAULO,Apelação no 0001033-06.2004.8.26.0642, 2015, p.7). 
também produzido a partir delas e de sua aplicação. Não se trata de realizar tão somente uma crítica acerca da justiça ou injustiça das normas jurídicas por sua colaboração com as desigualdades produzidas pelo capitalismo, mas, ao contrário, perceber "os sentidos ideológicos" ${ }^{\prime 4}$ por detrás da produção normativa e de sua utilização institucional no sistema de justiça, em nosso caso, do Poder Judiciário. Afinal, é por meio do discurso jurídico que o direito se relaciona com as relações sociais, sem se valer de um mecanismo necessariamente descritivo - que as indique explicitamente - mas por meio de "suposições tácitas", ocultas, que precisam ser investigadas (CORREAS, 1986. p. 49).

Durante as pesquisas, as estratégias argumentativas utilizadas pelos magistrados no enfrentamento à "questão social urbana", pertinente ao direito à moradia, se apresentaram no plural. Não foram raros os casos em que os juízes reforçaram sua solidariedade diante da situação das pessoas sem moradia, ainda que o resultado concreto do conflito possessório poucas vezes tenha refletido esse mesmo sentir. ${ }^{5}$ Para que esta multiplicidade de motivações pudesse ser conhecida, sistematizamos as linhas de argumentação em quatro vertentes que sintetizam os principais elementos justificadores das sentenças que afastaram o direito à moradia como razão para decidir.

Por óbvio que essa divisão tem por objetivo a criação de tipos ideais de racionalidade, cujas nuances nas decisões são marcadas por colorações mais ou menos expressivas. Reproduzimos trechos de decisões que colocam luz a essas características e que fornecem indícios que nos permitem explorar os percursos discursivos de construção da sentença. Por vezes, mais de um tipo de racionalidade foi aventado em uma mesma decisão. Além disso, em que pese as linhas de entendimento que iremos apresentar sejam amplamente majoritárias nas decisões pesquisadas, identificamos também vozes dissonantes que pontuaram criticamente o papel do Judiciário e as interpretações tradicionais acerca dos fenômenos urbanos.

\section{Argumentação $n .^{\circ} 1$}

\footnotetext{
${ }^{4}$ Nas palavras do autor: "Para la crítica delderecholo importante no sonlas normas en si mesmas y em tanto tales, sino laideologia que lasmismasreproducen cotidianamente al ser usadas, aunque, desde luego, para estudar la ideologia portada por las normas es necesario poder identificarlas: ladogmatica es ineludible; es necesarioconocerelderecho."(...) (CORREAS, 1986. p. 12)

5 "É evidente que muito me sensibiliza a petição do advogado subscritor da petição de fl. 115, acompanhada de inúmeras cartas dos ocupantes descrevendo suas necessidades e condições, inclusive sobre o período natalino que se avizinha, mas só posso me solidarizar e fazer cumprir a lei e a decisão proferida HÁ MAIS DE UM ANO”. (RIO GRANDE DO SUL, Agravo de Instrumento no70067772954, 2015,p. 3-4).
} 
Os fatos são admitidos pelos agravantes, que divergem apenas quanto à data em que se deu a ocupação. Nos termos do art. 927 e 928 do CPC, provada a posse, o esbulho e a perda da posse, o juiz reintegrará liminarmente o autor na posse do bem. É simples assim. A lei não permite ao magistrado deferir a posse a quem a ela não tenha direito e confessadamente não tenha domínio a opor ao autor; ou, em outras palavras, a lei não permite ao juiz recusar a posse a quem a ela faça jus. (SÃO PAULO, Agravo de Instrumento $n^{\circ}$ 2141037-59.2015.8.26.0000, 2015, p. 5).

Com forte inspiração privatista, esta primeira modalidade de racionalidade interpreta o conflito social da disputa fundiária a partir das categorias tradicionais de posse e propriedade edificadas na tradição civilística. Sob este viés, os interesses em enfrentamento são dimensionados à literalidade da lei civil, compreendendo a posse como manifestação da exterioridade da propriedade, independentemente de outros diplomas normativos que possam ser cotejados e, inclusive, a despeito da principiologia constitucional e a consequente vinculação entre tutela possessória e cumprimento da função social da propriedade.

É a linha argumentativa mais comumente identificada nas decisões, que se caracteriza pela descontextualização do conflito fundiário coletivo de suas especificidades, tratando-o como disputa individual entre proprietários e não proprietários sob a guarida exclusiva do código civil e do respectivo diploma processual. Nessa forma de construção da solução jurisdicional, os conflitos são abordados de maneira simplificadora já que particularidades como interesse social da demanda, quantidade de sujeitos atingidos com a remoção, dinâmicas socioespaciais de formação da ocupação informal - sequer são enfrentados na justificação decisória. Não por qualquer outra razão, os termos "despejo" ou "remoção forçada" não aparecem nas narrativas das sentenças. São substituídos pelas expressões "reintegração de posse" ou "desocupação", incorporadas nos códigos positivos privados e no senso comum jurídico.

Em situação bastante atípica na qual um Desembargador empregou o termo "despejo", em alusão ao conteúdo disposto no Comentário Geral $n^{\circ} 7$ do PIDESC $^{6}$, houve declaração de

\footnotetext{
${ }^{6}$ A ação mencionada refere-se à interposição de Agravo de Instrumento em ação de reintegração de posse, manejada pela Universidade de São Paulo face a ocupação de "réus desconhecidos" em um dos imóveis da autarquia com a finalidade de moradia. O juiz de primeiro grau indeferiu a concessão da reintegração em sede liminar, mesmo se tratando de bem de dominialidade pública. Irresignada, a autora interpôs o recurso com a intenção de obter a referida liminar. O Desembargador Relator, em decisão destacada em relação a todas as demais que foram analisadas, manteve o indeferimento da liminar. 0 caráter distinto da decisão, entretanto, refere-se aos argumentos que foram invocados pelo magistrado, com a utilização de diplomas internacionais de direitos humanos (Pacto Internacional de Direitos Econômicos Sociais e Culturais - Comentário Geral n.7); e direitos constitucionalmente assegurados como função social da propriedade, direito à moradia e o direito à dignidade da pessoa humana, os quais
} 
voto contrário com incisiva contestação acerca do cabimento jurídico de sua utilização. Inconformado com o quadro interpretativo apresentado no voto do relator, o magistrado discordante argumentou que a equiparação da reintegração de posse à noção de "despejo" estaria tecnicamente equivocada, na medida em que a situação em análise versaria sobre ocupação, inexistindo contrato de locação que pudesse dar suporte a um suposto "despejo". Mencionou ainda que a postura do Desembargador-Relator estaria pautada em argumentação executada "fora do quadro referencial que orienta o discurso jurídico", imputada como o lugar de fala ideológico de um "intelectual orgânico", com orientação evidentemente assistencialista (SÃO PAULO, Agravo de Instrumento n. 20150000707461, 2015). ${ }^{7}$

No desenrolar dessa mesma racionalidade, o direito à moradia não é tomado como um direito autônomo e, não raro, nem é mencionado como interesse a ser sopesado na indicação

possuem normatividade estariam sob violação na realização do despejo. A decisão merece ser reproduzida: "Observe-se que a reintegração da posse do imóvel objeto da demanda e a imediata demolição das moradias construídas na referida área pública provocaria o desabrigo de adultos e crianças em situação de hipossuficiência, o que vai de encontro com a razoabilidade devida, bem como representa uma afronta a um direito social constitucionalmente estabelecido. Note-se que, além de princípio, está erigido, como garantia constitucional, o direito à moradia digna, o qual constitui norma de ordem pública, dotada de imperatividade e inviolabilidade. Nesse sentido, importante consignar que esse direito foi reconhecido e implantado como pressuposto para a dignidade da pessoa humana, bem como recepcionado e propagado na Constituição Federal de 1988, em seu artigo 6으, caput. A dignidade da pessoa humana, como princípio normativo que é, atrai o conteúdo de todos os demais direitos fundamentais, bem como exige e pressupõe o reconhecimento e proteção dos referidos. Nesse diapasão, para a satisfação desse princípio maior dignidade, deve-se observar e preservar os direitos que lhes são inerentes, a exemplo do direito à moradia digna. Além disso, cabe destacar que não é ele garantido apenas nacionalmente, como também o é no plano internacional. Conforme a eminente ponderação realizadaJuízo a quo: “(...) o despejo forçado não deve ser a primeira, mas aúltima medida a ser tomada, como prevê oComunicado Geral n. 7 do Comitê de DireitosEconômicos, Sociais e Culturais. (...) ora, em um Estado Democrático de Direito, no qual se protege o exercício de garantias sociais e individuais dos seus cidadãos, não se poderia afastar um direito que constitui elemento fundamental para o exercício de outros. Assim, tem-se que o texto constitucional não pode ser resumido a um simples "catálogo de boas intenções". Da mesma forma, o direito à moradia digna nele previsto também não deve ser tomado como um mero exercício de retórica, que, embora positivado, não é a ele dada a eficácia devida. Ao contrário, a sua implementação no plano fático torna-se uma medida impositiva. “(...)nesses termos, entre proteger o referido direito social, que está intimamente atrelado à dignidade da pessoa humana, e fazer prevalecer, contra ele, um direito patrimonial, como o é o da propriedade privada, não restam dúvidas de que o primeiro deve prevalecer (...)". (SÃO PAULO, Agravo de Instrumento n. 20150000707461, 2015).

${ }^{7} \mathrm{Na}$ íntegra da crítica realizada pelo Desembargador, autor do voto vencido: "Ao tratar reintegração de posse como "despejo", ao defender que invasão de áreas públicas não comporta reintegração liminar (que a decisão trata como antecipação dos efeitos da tutela) porque isto implicaria violar o direito de "moradia digna" daquele que habita de forma indigna, está-se não só argumentando fora do quadro referencial que orienta o discurso jurídico, como também reforçando velhas práticas de assistencialismo (da qual os regimes de direita, no Brasil, usaram e abusaram), em vez de incentivar a solidariedade social e o desenvolvimento integral do homem, estes sim objetivos fundamentais da República Federativa do Brasil (art. 3o, I, III e IV, da CF) (...)". (SÃO PAULO, Agravo de Instrumento n. 20150000707461, 2015). 
do melhor resultado para o conflito. Em verdade, a argumentação transcorre com considerável grau de abstratalidade em que se discute a "melhor posse", compreendida desde um paradigma jurídico proprietário, como mencionamos no item anterior. A comprovação do domínio, por meio do título registral da propriedade e de elementos laterais, como pagamento do IPTU, são trazidos à tona para fundamentar a solução jurídica. Apesar de se tratar de situações inscritas na dinâmica territorial das cidades, e, portanto, elaboradas teoricamente em um ramo específico do saber jurídico voltado às matérias urbanísticas, o referencial teórico e doutrinário mobilizado nesse viés corresponde quase que exclusivamente a autores tradicionais do direito civil e do direito processual civil. ${ }^{8}$

Finalmente, por esta leitura jurídica, a função do afazer jurisdicional se circunscreve à aplicação técnica da lei ao caso concreto e se encerra na produção de uma resposta jurídica estabilizada por meio da sentença. As repercussões da reintegração de posse no plano fático não são problematizadas no julgamento, até porque, sob tal interpretação, não constituem objeto próprio do direito nem se apresentam como responsabilidade a ser enfrentada pelo Poder Judiciário. Aproximam-se mais do modelo jurisdicional apresentado por François Ost (1985, p. 12) como "modelo legalista-liberal", forjado no contexto de surgimento dos Estados liberais e, rearticulado, acrescentamos nós, na conjuntura de rearranjo neoliberal que perpassa as instituições.

Para Ost (1985, p. 12), os afazeres desempenhados pelo juiz do modelo liberal contextualizam-se metodologicamente com o recurso à lógica formal e à utilização de instrumentais que compreendem a interpretação da lei a partir da combinação de premissas maiores e menores (silogismos). Atua nesse espectro a força do legislador racional, como elemento integrador do direito e mantenedor da estabilidade e da coesão social. A legitimidade do direito para o modelo de justiça liberal-legalista reside, precipuamente, na verificação de sua validade (como procedimento) muito mais que a conferência de sua adequação do ponto de vista do conteúdo material. É por tal razão que a construção da noção de "justiça", nesse paradigma, perfaz-se pela observância da

\footnotetext{
${ }^{8}$ A doutrina mencionada corresponde aos seguintes autores civilistas e processualistas: Adroaldo Furtado Fabrício; Araken de Assis; Silvio de Salvo Venosa; Arnaldo Rizzardo; Renan Falcão de Azevedo; Lafayete; Savatier; Arruda Alvim; Pontes de Miranda; Caio Mário;Cândido Rangel Dinamarco; Carlos Roberto Gonçalves;Cristiano Chaves de Farias e Nelson Rosenvald; E.D. Mouniz de Aragão; ElpídioDonizetti; Arnaldo Rizzardo; FlávioTartuce e José F. Simão;Nelson Nery Junior e Rosa Maria de Andrade Nery;Fredie Didier Júnior; Humberto Theodoro Júnior; MiguelReale; Orlando Gomes; Washington de Barros Monteiro; Theotonio Negrão.
} 
coerência interna do sistema jurídico, em sua elaboração e aplicação uniforme e pretensamente imparcial (OST, 1985, p. 12).

Na crítica do autor, esta lógica formal, entretanto, não se adapta às exigências da sociedade pós-industrial. Nesse novo contexto, o juiz é chamado a dirimir conflitos em uma perspectiva mais ampla que compreenda a realização de políticas, por meio de uma racionalidade instrumental e teleológica. Destacam-se, aqui, as finalidades que serão (ou não) atingidas a partir de determinada solução jurisdicional e suas implicações econômicas, sociais, ou nas mais diversas áreas afins. Para que isso seja possível, a tarefa deste outro modelo jurisdicional a ser construído (OST, 1985, p. 20-21) ${ }^{9}$ perpassa tanto pelo tratamento das normas jurídicas como pela interlocução com outros saberes que sejam demandados no caso concreto. Essa racionalidade, portanto, destaca-se por seu caráter da adequação, desempenho e eficiência nos meios empregados aos fins obtidos (OST, 1985, p. 22).

\section{Argumentação $n .^{\circ} 2$}

Deliberações desse jaez, ainda que possam ser consideradas justas, são próprias e exclusivas do Poder Executivo, ou, em certas situações, do Poder Legislativo, refugindo, portanto, ao âmbito de atuação do Judiciário, reservado, por preceito constitucional, ao reconhecimento e proteção dos direitos subjetivos (...). (RIO GRANDE DO SUL. Apelação Cível $\left.n^{\circ} 70059976944,2014\right)$.

A discussão sobre a função institucional do Poder Judiciário é o núcleo o que fundamenta uma segunda modalidade de racionalidade argumentativa nas situações de conflito fundiário, na qual a aplicação do direito à moradia e da função social da propriedade extrapolam suas competências.

Nas decisões que se alinham a este prisma interpretativo, o direito à moradia é compreendido como norma programática, cuja aplicação se viabiliza exclusivamente pelos atos do Estado-administrador ou do Estado-legislativo. Como explicitado em acórdão proferido no Tribunal de Justiça do Distrito Federal e Territórios (Apelação no 20090111961262, 2014, p. 31), "o comando que está impregnado no artigo 6o do texto constitucional, que erigira a moradia como

\footnotetext{
${ }^{9}$ No âmbito do modelo de justiça normativo-tecnocrático, muito embora o princípio da separação dos poderes não seja colocado em xeque, notam-se profundas alterações no perfil da atuação do juiz. A atividade jurisdicional distancia-se do lugar de isolamento que ocupava no liberalismo, e passa a aproximar-se das discussões políticas e da atuação ativa por parte do juiz. Encontram-se aí afazeres como a significação de conceitos indeterminados, a formulação de novas respostas às demandas de interesse coletivo, etc. Ou seja, o juiz passa a atuar politicamente, aproximando-se em certa medida à atuação da Administração, e não estando mais restrito à mera subsunção dos textos legais ao caso concreto. (OST, 1985, p.20-21).
} 
direito social, está revestido de conteúdo meramente programático, não encerrando nenhuma norma de eficácia material, muito menos passível de ser içada como lastro para imiscuir-se nas relações de direito privado $(. . .)^{\prime \prime}{ }^{10}$

Portanto, sob essa compreensão acerca da separação dos poderes no Estado Democrático, a participação do Poder Judiciário estaria limitada ao reconhecimento dos direitos subjetivos, individuais, sob pena de comprometimento da "segurança jurídica, na qual repousa toda a esperança de harmonia social, com ressonância negativa no próprio Estado de Direito, sobre o qual se esteia o regime democrático" (RIO GRANDE DO SUL, Apelação Cível no 70059976944, 2014, p. 9). Em uma aproximação mais cuidadosa sobre a repercussão desta compreensão na administração jurisdicional dos conflitos, vê-se que a justiciabilidade dos direitos sociais, a exemplo do direito à moradia, é contida porquanto resguardada tão somente ao Poder Executivo, responsável originário da promoção de políticas públicas voltadas a este fim. ${ }^{11}$

Por diversas vezes o enfrentamento do argumento apresentado pelos réus acerca da violação do direito à moradia em função do despejo é afastado com a justificativa de que tal situação corresponde a um "problema social" que não pode ser resolvido na seara do Poder Judiciário. Especialmente em detrimento do direito subjetivo do particular cuja propriedade tenha sido supostamente esbulhada por meio da invasão. A alegada "abstratalidade" do

\footnotetext{
${ }^{10} \mathrm{Na}$ íntegra da citação: "Outrossim, o comando que está impregnado no artigo 6o do texto constitucional, que erigira a moradia como direito social, está revestido de conteúdo meramente programático, não encerrando nenhuma norma de eficácia material, muito menos passível de ser içada como lastro para imiscuir-se nas relações de direito privado, cuja tutela, como é cediço, observados os delineamentos constitucionais, circunscreve-se ao tratamento que the é dispensado pela legislação infraconstitucional. Aliás, aludido regramento, ainda que efetivamente estivesse revestido de conteúdo prático e eficácia material, estaria destinado exclusivamente ao poder público, a quem está endereçada a obrigação de viabilizar o alcance e materialização dos direitos sociais, e não ao cidadão, pois, ainda que instado moralmente a concorrer para o bem-estar do próximo, não está compelido a ficar privado do que the pertence como forma de contribuir para o bem comum. Ou seja, a propriedade privada não pode ser ocupada e socializada sob o prisma da materialização do direito de índole constitucional pertinente à moradia". (DISTRITO FEDERAL E TERRITORIOS, Apelação no 20090111961262, 2014, p. 31).

11 "(...) 4. Muito embora nenhuma lesão possa ser afastada do Poder Judiciário (art. 5o, XXXV, da Constituição Federal), compõe atribuição do Poder Executivo, sob critérios objetivos preestabelecidos, gerir a ocupação do espaço urbano, mediante aprovação de projeto, expedição de termos de ocupação e de alvarás de construção. 5. Ao Judiciário é resguardado exclusivamente o controle da legalidade da atuação administrativa, não Ihe sendo lícito imiscuir-se no mérito do ato administrativo, donde resulta que não pode interferir na condução das políticas públicas, ainda que revestidas de interesse e alcance sociais, competindo ao interessado inscrever-se e participar dos programas sociais de conformidade com o legalmente estabelecido, ficando reservada à tutela jurisdicional apenas o controle da observância dos parâmetros positivados (...)". (DISTRITO FEDERAL E TERRITÓRIOS, Agravo Regimental no Agravo de Instrumento no 20140020149982, 2014, p. 3).
} 
direito $^{12}$ à moradia é, assim, contraposta à solidez da necessidade de se salvaguardar a esfera patrimonial do particular. Ainda que sob percurso diverso, a estratégia permite que a decisão que autoriza a reintegração de posse se desincumba de discutir a repercussão social e o destino das famílias que serão despejadas. Isso seria tarefa e responsabilidade afeta à Administração Pública. Nas poucas situações em que se identifica alusão ao destino da realocação dos moradores, especialmente em situações vinculadas ao despejo em áreas públicas, o magistrado aponta para a necessidade - também genérica - de cadastro dos atingidos e inclusão em "programas habitacionais".

O afastamento da aplicabilidade do direito à moradia por seu caráter meramente programático, ou ainda, por seu descabimento como solução a ser administrada pelo Poder Judiciário nos conflitos entre particulares, não encontra guarida em grande parte da doutrina constitucionalista brasileira contemporânea. Dedicando-se à análise dos direitos fundamentais classificados sob a denominação de normas constitucionais de cunho programático, Ingo Sarlet(2015, p. 301) esclarece que não são elas "meras proclamações de cunho ideológico ou político", mas genuínas normas jurídicas com potencialidade para gerar efeitos jurídicos, inclusive mediante sua aplicação pelos órgãos judiciários. ${ }^{13}$ Aliás, como defende o autor, não há direito fundamental que não possua aplicabilidade imediata a ser derivada do próprio texto da Constituição.

No que se refere à natureza dos direitos sociais fundamentais, como o direito à moradia, é preciso lembrar que possuem sempre caráter "multifuncional" que abrange o dever da não interferência indevida por terceiros e, também, uma atuação positiva consistente no caráter prestacional do Poder Público em prover o acesso universal ao bem jurídico revestido

\footnotetext{
12 "Nesse contexto é que se sustenta ser legítima a reintegração em face de esbulho possessório, ainda que seja reconhecido o direito abstrato à habitação que no local pretendam os ocupantes, precariamente, instalar; e que a autoridade jurisdicional e a condição de agente político do Estado requer do juízo a sensibilidade para administrar a justiça e adotar as medidas necessárias ao cumprimento das decisões sopesando as peculiaridades do caso concreto e a concessão ou eventual dilação do prazo de desocupação. O tempo concedido facilitará a ação da Secretaria de Habitação que deve ser instada a orientar a saída dos ocupantes, antes de ser requisitada a intervenção da força pública para eventual desocupação forçada". (RIO GRANDE DO SUL, Agravo de Instrumento no 70067813790,2015, p. 9).

13 “(...) Neste contexto, consideramos possível a premissa de que todas as normas da Constituição aptas a serem e enquadradas no grupo das normas de cunho programático apresentam um elemento comum que justifica suficientemente esta opção, qual seja, o de que todas estas normas se caracterizam pelo fato de reclamarem, para que possam gerar a plenitude de seus efeitos, uma interposição do legislador. Cuida-se, portanto, de normas que apresentam a característica comum de uma (em maior ou menor grau) baixa densidade normativa, ou, se preferirmos uma normatividade insuficiente para alcançarem plena eficácia, porquanto se trata de normas que estabelecem programas, finalidades e tarefas a serem implementados pelo Estado, ou que contêm determinadas imposições de maior ou menor concretude dirigidas ao Legislador (...)". (SARLET, 2015, p. 301).
} 
de fundamentalidade. O direito fundamental à moradia, nesse espectro, como exemplifica Daniel Hachem (2014, p. 137), demanda não apenas a promoção do acesso à moradia adequada, "mas também o direito de não ser despejado de maneira arbitrária ou de não ser objeto de cláusulas abusivas num contrato de aluguel".

Desse modo, em relação à obrigação negativa do Poder Público de outros particulares acerca da não violação do direito à moradia, constitutiva da "função defensiva" que integra sua natureza, não há dúvidas de que a aplicação é juridicamente possível e constitucionalmenteassegurada sem que se vislumbre seu caráter de abstratalidade, como mencionam certas decisões. Ao contrário, como indica Hachem (2014, p. 139-140), a "vagueza" na determinação do conteúdo jurídico de direitos fundamentais não é circunscrita ao âmbito dos direitos sociais e pode ser encontrada em direitos fundamentais vinculados à liberdade como a liberdade religiosa ou a liberdade de expressão -, cujas fronteiras para o exercício, longe de estarem bem demarcadas pelo texto constitucional, não prejudicam sua larga aplicação pelo Poder Judiciário, sem maiores dificuldades. ${ }^{14}$

A invocação do direito à moradia como um direito de defesa, portanto, encontra previsão no Art. $5, \S 1^{\circ}$ da Constituição Federal e vincula a atuação jurisdicional, que deverá zelar "por sua máxima eficácia e efetividade" (SARLET, 2009-2010, p. 33). A justiciabilidade dos direito à moradia pode ocorrer tanto pela via do controle constitucional - difuso e concentrado - em face de eventuais restrições promovidas pelo Poder Público ou por outros particulares, como também pela interpretação da legislação infraconstitucional à luz da nos normas dos direitos fundamentais (SARLET, 2009-2010, p. 33).

Nos casos de disputas fundiárias que se inscrevem na colisão entre o direito à moradia frente aos outros direitos fundamentais - como o direito de propriedade, por exemplo - o direito à moradia deve ser considerado como um direito fundamental com

14 "Os direitos de liberdade também podem não estar plenamente determinados pelas normas constitucionais. A vagueza é uma característica que não acomete apenas os direitos sociais. Assim como é difícil delimitar o conteúdo do direito fundamental à moradia, os contornos precisos do direito à liberdade religiosa podem gerar sérios questionamentos em determinados casos, frente à ausência de uma regulamentação legislativa. Até que ponto vai a liberdade de consciência numa situação em que um menor de idade internado em um hospital precisa de uma transfusão de sangue para sobreviver e os pais não a autorizam por motivos religiosos, como ocorre com as testemunhas de Jeová? O mesmo se diga quanto ao direito à liberdade de expressão: ele engloba, entre as suas faculdades, o direito de manifestação de pensamentos preconceituosos? (...)Desta sorte, o argumento de que a necessidade de regulamentação legislativa retira dos direitos fundamentais sociais a sua jusfundamentalidade porque impede a sua pronta justiciabilidade é falacioso, uma vez que essa peculiaridade obsta a exigibilidade imediata da dimensão prestacional de todos os direitos fundamentais, sejam eles de liberdade ou sociais (desde que não seja possível extrair desde logo da Constituição os traços que configuram o conteúdo jurídico das prestações em questão)".(HACHEM, 2014, p. 139-140). 
eficácia plena e aplicabilidade imediata que merece ser sopesado em sua máxima potência. Ademais, conforme afirma Sarlet (2009-2010, p. 33), nas hipóteses em que se fizer necessária a "ponderação de bens e interesses" deverá o magistrado guiar-se pela solução jurídica que melhor hierarquizar os valores jurídicos contrapostos no caso concreto, tomando-se como referência o norte axiológico fixado pela dignidade da pessoa humana. Há, nestes casos, um "forte ônus argumentativo" 15 imposto ao magistrado que demanda a justificação das razões de decidir que viabilizam a flexibilização do direito à moradia diante de outro direito fundamental priorizado na situação analisada.

E, mesmo nos casos em que o direito fundamental à moradia não seja considerado como aquele que deva prevalecer no caso concreto, a exemplo das situações em que se autorizam os despejos forçados, é dever do Poder Público realizar todas as diligências necessárias para evitar que a violação do direito à moradia das famílias despejadas seja ainda mais gravosa. Evidente que reside aí um paradoxo, dado que a remoção das pessoas de seu local de moradia é, por definição, violadora de direitos. A despeito disso, as decisões que admitem a concessão de mandados de reintegração de posse devem, obrigatoriamente, conter os danos causados pela violação do direito fundamental, por meio da indicação de mecanismos dirigidos à mediação dos impactos da remoção, especialmente em se tratando de coletividades, com expressiva repercussão social.

Assim, além da indicação específica de parâmetros não arbitrários e violentos para o ato da desocupação, defendemos que o magistrado ao deferir a reintegração de posse deva ocupar-se também do destino habitacional que será dado às famílias removidas. A perspectiva de que os desdobramentos da despossessão pertinentes à solução de moradia dos réus não alcançam os efeitos da decisão sobre o conflito fundiário contraria o próprio texto constitucional, além dos diplomas internacionais que já foram mencionados. De modo que, não apenas é necessária a interferência jurisdicional acerca da solução habitacional ofertada às

\footnotetext{
15 "(...)Nota-se que as consequências práticas da aplicabilidade imediata, tanto em relação à dimensão objetiva quanto a dimensão subjetiva limitada das normas de direitos sociais, referem-se à possibilidade de, na medida de sua eficácia, ter alguma aplicação direta, sem necessidade de intermediação legislativa - é o que se denomina de eficácia plena. Como resultado, os órgãos estatais têm a tarefa de maximizar a eficácia desses direitos, o que atribui ônus argumentativo forte de fundamentaçãodos casos de ausência de concretização do direito fundamental. A doutrina considera como possíveis efeitos desta fundamentalidadeformal e material, aplicabilidade imediata, eficácia plena e realização progressiva, alguns efeitos práticos exigíveis:i) evitar medidas deliberadamente regressivas em matéria habitacional; ii) dedicar o máximo de esforços e o máximo de recursos para que o direito seja efetivado no menor prazo possível, sendo dada prioridade para os casos mais urgentes;iii) sempre satisfazer ao menos 0 conteúdo mínimo do direito, mesmo nos momentos de recessão ou crise". (FRANZONI, 2014, p.982).
} 
pessoas afetadas pelo despejo, como também tal atuação deve se dar com razoável concretude na garantia do direito violado, sendo insuficiente a determinação genérica de inclusão das famílias em cadastros de programas habitacionais, com tempo indeterminado para consecução.

\section{Argumentação $\mathrm{n} \cdot{ }^{\circ} 3$}

Não se pode tolerar, com a invocação do problema social a violação às regras que tutelam o direito de propriedade e o direito de posse, com a intenção deliberada de invasão. Os problemas sociais devem ser solucionados, com certeza, nas nunca desta maneira, com invasão. Assim agindo, caracterizaram o seu comportamento como contrário ao ordenamento jurídico. Cometeram esbulho possessório, com demarcação e construções sobre o imóvel de propriedade e posse da empresa requerente. Não podem, pois, merecer qualquer proteção legal. (RIO GRANDE DO SUL, Agravo Interno n 70062200100,2014 , p. 5)

A identificação das ocupações como uma conduta antijurídica que deve ser repreendida pelo Poder Judiciário, acima de qualquer circunstância, conforma a terceira vertente de interpretações que balizam o entendimento nas decisões analisadas. Nesta leitura a ênfase recai sobre o caráter reprovável da conduta praticada pelos "invasores" e seu potencial ofensivo à ordem pública ${ }^{16}$, à ordem jurídica e à ordem urbanística. Assim, ainda que a ausência de acesso à moradia seja reconhecida do discurso jurisdicional, a evidência da ocorrência da invasão impede sua inclusão como um direito a ser ponderado no caso concreto.

É como se a escolha dos moradores pela via da ocupação os deslocasse para um campo da ilicitude, de interdito jurídico, que impediria o reconhecimento de quaisquer direitos que pudessem ser aferidos a partir daí. De maneira implícita, ou por vezes, explícita, afere-se que a realização de ocupação - nomeada invasão - para fins de moradia implica a assunção do risco de ser despejado e de ter seu local de moradia submetido à permanente condição de insegurança, em uma renúncia tácita de direitos que ocorrera no ato da invasão.

Há, portanto, uma deslegitimação da conduta praticada e consequentemente das coletividades que a praticaram em sua condição de sujeitos de direitos. O sentido por detrás

16 Portadora de conteúdo jurídico indeterminado, a noção de "ordem pública" foi apresentada em decisão proferida pelo Tribunal de Justiça do Pará: "Assim, acrescenta-se a ideia de que a ordem pública representa uma situação de normalidade na consecução dos serviços públicos e atos administrativos, de modo que não haja prejuízo para a organização da Administração Pública por imposição externa". (PARÁ, Pedido de Suspensão de Medida Liminar no 0007754-07.2015.814.0000, 2015, p. 5). Note-se que tal definição deslegitima todo e qualquer ato de resistência e reivindicação política que venha a ocorrer no contexto do Estado Democrático de Direito, já que tais manifestações caracterizam-se justamente pela "perturbação" do "estado de normalidade", com vistas, muitas vezes, ao questionamento dos critérios de legitimação e justiça desta própria normalidade. Ou seja, por esta perspectiva, os conflitos urbanos em qualquer de suas expressões - atos, manifestações, ocupações - são elementos de desordem que precisam, em consequência, ser contidos e eliminados. 
dessa racionalidade foi bem explicitado em parecer do Ministério Público do Rio Grande do Sul, replicado em decisão que confirmou a concessão de liminar em reintegração de posse, "(...) Não acredito, em casos tais, na aplicação do refrão, imortalizado por Vandré, de que "quem sabe faz a hora, não espera acontecer (...)". Não é através da chamada força própria proibida, da burla à lei, que se dará dignidade e cidadania para aqueles que menos têm". ${ }^{17}$

A função do Poder Judiciário, nessa perspectiva, corresponde à repreensão das invasões diante do seu conteúdo essencialmente negativo. E a noção de essencialismo da conduta, nesse contexto, parece aplicar-se perfeitamente. A invasão, compreendida como transgressão, usurpação, violação da propriedade privada ou pública é tomada como um quadro referencial $a$ priori, que encerra qualquer outra ponderação que poderia ser realizada acerca dos interesses e direitos em conflito. Por isso, não raro encontraram-se afirmações como "o descumprimento da função social da propriedade não confere ao particular o direito de invadir" 18 ou "ainda que a área estivesse abandonada, a sanção respectiva deveria partir da administração pública e não de outros particulares". Mesmo sem maiores descrições dos elementos que compõem o tipo nomeado pela legislação como "esbulho", a conduta da invasão se desdobra no reconhecimento da prática esbulhadora, com a atribuição consequente das qualidades de "clandestinidade, violência e precariedade" na constituição do vínculo entre os moradores e a área que ocupam.

Especialmente as noções de violência e clandestinidade merecem aqui ser melhor exploradas. Na totalidade dos casos estudados em que houve a configuração em juízo de posse injusta, com a menção explícita destes atributos, pouco ou nada se justificou acerca das condutas que embasavam sua utilização. Retornamos ao epicentro proprietário como núcleo irradiador da justificação, portanto. Uma vez consolidada a ocupação de área, sem que os ocupantes detenham o título formal de propriedade, a violência e a clandestinidade do ato são

\footnotetext{
$17 \mathrm{Na}$ completude do trecho replicado na decisão: "O caso em exame é um exemplo concreto de como se "resolve" muitas vezes a questão da moradia popular em nosso país. Não acredito, em casos tais, na aplicação do refrão, imortalizado por Vandré, de que "quem sabe faz a hora, não espera acontecer". Hoje existem políticas habitacionais para a população de baixa renda, como o "Minha Casa, Minha Vida". Não é através da chamada força própria proibida, da burla à lei, que se dará dignidade e cidadania para aqueles que menos têm. Assim, tendo o autor da possessória, ora agravado, demonstrado o aperfeiçoamento dos requisitos legais previstos no artigo 927 do Código de Processo Civil, nenhum reparo à liminar deferida pelo julgador singular." (MINISTÉRIO PÚBLICO DO RIO GRANDE DO SULApud RIO GRANDE DO SUL, Agravo de Instrumento no 70062538723, 2015, p. 8).

18 "Ademais, eventual penalidade pelo não cumprimento da função social da propriedade, como a desapropriação, por exemplo, deve partir de iniciativa estatal, por meio dos órgãos e meios adequados, ou então por meio de processo de usucapião, que não é o caso dos autos." (PARÁ, Agravo de Instrumento no 0095731-37.2015.8.14.0000, 2015. p. 3).
} 
deduzidas da própria condição não proprietária dos sujeitos. Em outras palavras, sob essa visão a própria existência das ocupações é violenta, clandestina e precária porquanto transgressora da ordem proprietária hierarquicamente superior na estruturação da mentalidade jurídica (e jurisdicional) majoritária. E essa violência supera a situação objetiva da disputa entre posse e propriedade travada entre os sujeitos processuais e ganha dimensão de violação à ordem justamente por seu potencial desestabilizador da organização legitimada sob a segurança jurídica do título de propriedade.

\section{Argumentação $n .^{\circ} 4$}

Na ponderação de valores constitucionais, o direito à moradia não pode sobrepor-se ao interesse e direito da coletividade em possuir um meio ambiente equilibrado (art. 225, caput da CF) e um adequado ordenamento urbano (art. 182, caput, da CF), sob pena de grave desequilíbrio do sistema normativo de regulação social (...). ${ }^{19}$ (DISTRITO FEDERAL E TERRITÓRIOS, Agravo Regimental no Agravo de Instrumento № 20140020149982, 2014, p. 2).

A última vertente argumentativa conecta-se especialmente aos casos em que o imóvel em litígio envolve área de interesse ambiental. Nas decisões pesquisadas, 37 casos correspondem a situações conflitivas nas quais a variável ambiental se fez presente e influenciou as razões de decidir expostas pelo magistrado. Nessas ocorrências, paralelamente às racionalidades argumentativas já comentadas, verificou-se um reforço de justificação das remoções sob o embasamento da violação de um direito transindividual - o direito ao meio ambiente equilibrado - que estaria sob ameaça a partir da conduta dos ocupantes.

Apesar de envolver situações coletivas, nestes casos o direito à moradia é compreendido como um direito individual que, embora legítimo, não pode obstaculizar o direito de todos ao meio ambiente saudável. Há um conflito, ao menos aparente, entre direito à moradia e direito ao meio ambiente. Em verdade, as entrelinhas dessa modalidade discursiva posicionam o morador das ocupações irregulares como uma ameaça ambiental. Esse discurso,

\footnotetext{
${ }^{19}$ Na íntegra: "O fato de estar a invasão consolidada e de haver a prestação de serviços públicos, como energia, não tem o condão de ilidir a ilicitude da situação. A lei não é revogada pelo costume, e tem vigência até que outra a revogue ou modifique (...). Na ponderação de valores constitucionais, o direito à moradia não pode sobrepor-se ao interesse e direito da coletividade em possuir um meio ambiente equilibrado (art. 225, caput da CF) e um adequado ordenamento urbano (art. 182, caput, da CF), sob pena de grave desequilíbrio do sistema normativo de regulação social. Nem mesmo a ausência ou insuficiência de políticas públicas voltadas à outorga do direito social de moradia previsto no art. 6 o da Constituição Federal autorizam a potestatividade com a qual os recorrentes autores vieram a ocupar terreno público e nele edificar sem autorização administrativa ou planejamento do desenvolvimento urbano da cidade". (DISTRITO FEDERAL E TERRITÓRIOS, Agravo Regimental no Agravo de Instrumento no 20140020149982 , 2014, p. 2).
} 
aliás, não é novo nem exclusivo das ocupações urbanas para moradia. ${ }^{20}$ Inscreve-se no que José Sérgio Leite Lopes denominou "ambientalização dos conflitos sociais" (LOPES, v. 12, n. 25, p. 31 64) e corresponde à incorporação da pauta ambiental como estratégia discursiva que desloca os interesses em disputa tomando como central a agenda de proteção ao meio ambiente. Como adverte Compans (2007, p. 84), em se tratando de ocupações irregulares, esse deslocamento discursivo "tem sido instrumentalizado por determinados agentes sociais para pressionar o poder público a retomar a política de remoções de favelas". ${ }^{21}$

Ocorre que, apesar do princípio da não remoção de favelas ter sido incorporado ao conjunto legislativo incidente sobre matéria urbanística, elaborado após a Constituição de 1988, persistiu a possibilidade de retirada da população moradora quando se tratar de "unidades de conservação" ou de "áreas de risco" (COMPANS, 2007, p. 84). A partir daí, inaugurou-se um embate técnico e discursivo que se tornou decisivo para viabilizar a permanência das ocupações ou apontar para a necessidade de sua retirada do local, em função do interesse ambiental subjacente. E é evidente que a seleção administrativa das áreas que não devem comportar assentamentos humanos não está alheia a dinâmica imobiliária e de valorização dos espaços das cidades.

Ao contrário, como aponta Compans (2007, p. 84), trata-se de um movimento com duas faces complementares. A delimitação pela legislação ambiental das áreas que devem ser protegidas favorece a ocupação informal pela população de baixa renda já que, ao menos em um primeiro momento, esses locais são retirados do mercado imobiliário formal. As áreas com restrições de origem ambiental conformam-se como espaços excedentes, menos valorizados, justamente pelas limitações que condicionam a sua utilização e, consequentemente, acabam sendo utilizados como solução de moradia por quem não acessa as áreas regularizadas da

\footnotetext{
${ }^{20}$ Veja-se, por exemplo, as situações de remoções forçadas que envolvem comunidades tradicionais, comunidades indígenas e mesmo assentamentos rurais de reforma agrária. O conflito aparente entre a presença destas comunidades e a preservação ambiental foi objeto de reflexão em outra oportunidade: "Dessa forma, o conflito entre a existência territorial das comunidades quilombolas e a preservação da biodiversidade deve ser compreendido como um falso antagonismo, no qual a natureza e a ecologia são manipuladas como dados ideológicos que encobrem os conflitos sociais que Ihes são subjacentes. Até mesmo porque, como relembra Milton Santos, em boa parte dos casos os mesmos atores que agenciam "certa pregação ecologista-naturalista" são financiados por aqueles que lucram com o processo de "globalização perversa", maior responsável pela degradação da natureza(...)".(MILANO, 2011. p.128). A este respeito, consultar: GEDIEL, 2015; SANTILLI, 2005; SANTOS,2009.

${ }^{21}$ Os exemplos de despejos forçados justificados pelo argumento de proteção ambiental são múltiplos. A região do Horto, contígua ao Jardim Botânico do Rio de Janeiro, é mais uma destas situações nas quais o conflito se estabelece na (aparente) incompatibilidade entre a permanência das comunidades e a tutela do interesse ambiental. A este respeito, ver: F.L.J., s.d.
} 
cidade. Por outro lado, essa mesma legislação "vem proporcionando uma nova justificativa para a contenção ou mesmo a remoção destes assentamentos informais".

Esse interdito ambiental às ocupações informais é fortalecido com a construção discursiva da noção de risco. O risco ambiental é tomado como consequência da existência das favelas, que prejudicam a coletividade dos habitantes da cidade, "seja pela possibilidade de ocorrência de desastres naturais, seja pelas características próprias da ocupação - como a falta de saneamento e elevada densidade populacional etc. - enquanto fatores de degradação do meio ambiente urbano" (COMPANS, 2007, p. 84). Nas decisões pesquisadas que versavam sobre áreas de interesse ambiental, o argumento do risco pode ser identificado em determinadas narrativas, com essa dupla dimensão. A presença das ocupações ocasiona situação de risco para o meio ambiente, com repercussões que atingiam tanto o conjunto da cidade como os moradores residentes.

Em Recurso Especial interposto junto ao Superior Tribunal de Justiça (BRASIL, Recurso Especial n. $1.034 .134-R J, 2008)$, acerca da remoção de famílias que ocupavam área pública, no município de Belford Roxo, a sentença original que autorizou a desocupação fundamentou-se na argumentação "de que as construções irregulares foram edificadas em logradouro público e não foram licenciadas, violando o Código de Obras do Município e sua legislação urbanística, além de enquadrarem-se no conceito de poluição, previsto no $\operatorname{Art.} 3^{\circ}, \mathrm{III}, \mathrm{c}$, da Lei Federal n. ${ }^{\circ}$ 6938/81". Nessa justificativa, a remoção da ocupação subsidiou-se em seu descabimento em face das normas urbanísticas e, também, na equiparação do assentamento informal à noção de "poluição" prevista na lei federal citada, que corresponde à Política Nacional do Meio Ambiente.

Em tais parâmetros legislativos será poluição a "degradação da qualidade ambiental resultante de atividades que direta ou indiretamente (...) afetem desfavoravelmente a biota", hipótese prevista na alínea "c" do dispositivo legal. O que se está a dizer, portanto, é que a "favela" mencionada na sentença é, em si, um elemento de risco ambiental que ocasiona — por suas características de irregularidade - um dano ao meio ambiente e aos demais moradores do entorno. A decisão foi mantida pelo STJ.

Com base em tais fundamentações, têm-se a dupla penalização dos pobres da cidade e o reforço à "injustiça ambiental", de que nos fala Henri Acselrad. Se a pauta da preservação ambiental alçou proporções globais nas últimas décadas, comprovadamente os agentes que mais sofrem com sua violação cotidiana são as coletividades de baixa renda, com características de classe e raça determinadas, que na falta de opções de moradia acabam por ocupar as 
localizações com maior vulnerabilidade ambiental (ASCELRAD, p. 5). ${ }^{22}$ E mesmo em tais circunstâncias, a existência destas coletividades é tomada como fator de incomodidade para o equilíbrio ambiental, cuja eliminação é frequentemente preferida em detrimento de outras soluções possíveis, como a elaboração de projetos de regularização fundiária que possibilitem o manejo sustentável das áreas em concomitância à presença dos moradores.

\section{CONSIDERAÇÕES FINAIS}

Carolina Maria de Jesus (1960, p. 38), mulher, negra, poeta do circuito periférico paulistano, ainda nos idos da década de 1960, descreveu em primeira pessoa as dores de ser o Outro na cidade grande: "Quando estou na cidade tenho a impressão que estou na sala de visita com seus lustres de cristais, seus tapetes de viludos, almofadas de sitim. E quando estou na favela tenho a impressão de que sou um objeto fora de uso, digno de estar num quarto de despejo". De lá para cá, o espaço urbano se afirmou, definitivamente, como o epicentro da sociabilidade humana. A promessa de civilização, que impulsionara a urbanização do início do século passado, concretizou-se em suas meias verdades como a edificação da cidade para alguns, tal qual previra Carolina. A segregação socioespacial e a desigualdade no acesso à cidade seguem relembrando que esta é sim o lugar dos encontros, mas que nem todos foram convidados a participar.

Desigualdade tão profundamente enraizada que chega a se acomodar no lugar do trivial, do naturalizado, alimentando o senso comum de que as coisas são assim porque sempre o foram. "É simples assim", como disse um magistrado ao reconhecer a reintegração de posse em um dos casos estudados. Na literatura especializada, entretanto, o desenvolvimento teórico significativo acerca da produção do espaço permitiu o desfazimento desses causalismosnaturalizantes. O que demonstrou que as subalternidades espaciais são, em verdade, produto da relação estreita entre tempo-espaço e as relações sociais. Dessa maneira, as desigualdades estruturantes entre as classes no capitalismo projetam-se ao espaço, não apenas como consequência de seu funcionamento, mas também como própria condição de possibilidade deste modo de produção.

A espacialização dessas relações capitalistas na produção das cidades nos permitiu dar um passo além. Compreender como, em cada local, sob a influência de arranjos políticos e culturais

\footnotetext{
22 "Se, por um lado, sabemos que os mecanismos de mercado trabalham no sentido da produção da desigualdade ambiental - os mais baixos custos de localização de instalações com resíduos tóxicos apontam para as áreas onde os pobres moram - não podemos desconsiderar, por outro lado, que é a omissão das políticas públicas que permite a ação perversa do mercado. A experiência do Movimento de Justiça Ambiental mostra como se pode organizar as populações para exigir políticas públicas capazes de impedir que também no meio ambiente vigore a desigualdade social e racial".(ASCELRAD, p. 5).
} 
distintos, a segregação pode operar. Isso inclui, no exemplo brasileiro, revisitar nosso passado de subserviência colonial e mesmo o processo de modernização conservadora, cujas consequências institucionais ainda se fazem sentir. E perceber que a irregular topografia da cidadania urbana é resultado de configurações econômicas e gestões políticas que ampliaram a distância entre os que estão dentro ou fora do jogo. E mais do que isso, que entre nós a propriedade privada da terra continua sendo um atributo conectado não apenas ao patrimônio, mas também à personalidade. Ser proprietário é tão importante quanto ter propriedade.

Viver sem propriedade na cidade é viver sob o interdito de não ser, num perigo redobrado e reverberante sob a forma de tensões e conflitos. Conflitos pelo direito a se deslocar, a participar politicamente, a morar com dignidade, enfim, pelo direito a existir na cidade. O Direito encontra a espacialidade como uma promessa de reviver a cidade-negada e permitir o acesso indistinto aos bens da vida por quem quer que seja. A Themis vendada da modernidade surge como panaceia da injustiça socioespacial.

E às portas da lei, quando os conflitos fundiários se desenrolam sem encontrar contenção em outras vias - como a eliminação física, a contratualização ou a mediação extrajudicial - são conduzidos ao Poder Judiciário na forma de ações judiciais. Dos sujeitos, múltiplos, fazem-se dois autor e réu. Das circunstâncias, trajetórias, interesses e repertórios de ação - causa de pedir e contestação. Da atuação jurisdicional, o dever de "dizer o direito" sob a régua da lei e as molduras da experiência, conformada nos limites processuais e desinformada de sua espacialidade relacional.

Nas centenas de decisões analisadas conhecemos pouco das trajetórias dos sujeitos em conflito e mesmo das circunstâncias desses próprios enfrentamentos. São todos invasores, desconhecidos, ignorados, outros ou, então, proprietários. Vivem em barracos, casebres, favelas, ou em lugar nenhum. Suas práticas e existências - perigosas ou não - passaram à sombra do discurso jurisdicional. O espaço, em regra, não interessa ao Estado-juiz. A expectativa de reconhecer os conflitos pelos olhos dos magistrados se mostrou uma experiência frágil, empobrecida e redutora, porque desconectada da vivacidade e multiplicidade que marcam as disputas espaciais na sociedade.

Em contrapartida, se os conflitos foram registrados por meio de uma equação repetitiva, formulada invariavelmente em torno da proteção do direito de propriedade, o Poder Judiciário em seus afazeres pode ser melhor compreendido. Pela análise da obra nos aproximamos do autor. $\mathrm{E}$ traçamos um comportamento típico que indica para uma atuação jurisdicional que privilegia o título de propriedade da terra como prova irrefutável; não invoca direitos humanos e direitos fundamentais como fundamentos da decisão; e não crê na responsabilidade de o próprio Poder Judiciário garantir a não violação e promover a efetivação do direito à moradia adequada. 
Esses indícios, colhidos na superfície das decisões, apesar de significativos sobre a interação do Poder Judiciário com os conflitos, nos pareciam ainda insuficientes. Era preciso densificar a análise tentando compreender o que se passava por entre as linhas das decisões e mesmo em seu silêncio. 0 desembaraçar das estratégias discursivas do processopermitiu que acessássemos outro plano possível para a leitura das decisões. Conhecemos então as limitações mais estruturantes na tradução processual do conflito, referentes a um lugar incômodo ocupado pelos conflitos sociais de caráter coletivo, pela reconstrução discursiva dos espaços informais de moradia de maneira desterritorializada e estigmatizada e, finalmente, pela identificação do invasor - figura que se mostrou definitiva nos desfechos dos casos.

\section{REFERÊNCIAS BIBLIOGRÁFICAS}

ASCELRAD, Henri. Justiça Ambiental - novas articulações entre meio ambiente e democracia. Disponível em: <http: //www.ettern.ippur.ufrj.br/publicacoes/71/justica-ambiental-novasarticulacoes-entre-meio-ambiente-e-democracia>.

BRASIL. Superior Tribunal de Justiça. Recurso Especial n. ${ }^{\circ}$ 1.034.134-RJ (2008/0038197-8). Relator: M.H.M. Julgado em 21 de novembro de 2008.

COMPANS, Rose. A cidade contra a favela: a nova ameaça ambiental. InAnais do XII Encontro da Associação Nacional de Pós-Graduação e Pesquisa em Planejamento Urbano e Regional. Belém: 2007.

CORREAS, Oscar. Introducción a la crítica delderecho moderno (esbozo). Puebla: Universidad Autónoma de Puebla, 1986.

DISTRITO FEDERAL E TERRITÓRIOS. Tribunal de Justiça do Distrito Federal e Territórios. Agravo Regimental no Agravo de Instrumento no 20140020149982. Relator: Desembargador A.M. Julgado em 21 de agosto de 2014.

Tribunal de Justiça do Distrito Federal e Territórios. Apelação no 20090111961262. Relator: Desembargador T.C. Julgado em 21 de maio de 2014.

F.L.J. Diário de uma Invasora. Rio de Janeiro: Livre expressão editora, s.d.

FRANZONI, Júlia Ávila; LUFT, Rosangela M. Onde mora o direito à moradia? p.967-988. In CLÈVE, Clemerson Merlin. (coordenador) Direito Constitucional Brasileiro. Volume 1. Teoria da Constituição e Direitos Fundamentais. São Paulo: Editora Revista dos Tribunais, 2014.

GEDIEL [et.al] Direitos em conflito: movimentos sociais, resistência e casos judicializados: estudos de casos. v.1 e v.2. Curitiba: Kairós, 2015.

HACHEM, Daniel Wunder. Tutela administrativa efetiva dos direitos fundamentais sociais: Por uma implementação espontânea, integral e igualitária. Tese de Doutorado. Universidade Federal do Paraná. Curitiba, 2014. 
JESUS, Carolina Maria de. Quarto de Despejo - Diário de uma favelada. São Paulo: Editora Ática, 2001 (1960). p.38.

LOPES, José Sérgio Leite. Sobre processos de "ambientalização" dos conflitos e sobre dilemas da participação. Horiz. antropol, Porto Alegre , v. 12, n. 25, p. 31-64, June 2006 . Disponível em:<http://www.scielo.br/scielo.php?script=sci_arttext\&pid=S0104-

$71832006000100003 \&$ Ing=en\&nrm=iso>. Acesso em 12 de janeiro de 2016.

MILANO, Giovanna Bonilha. Território, cultura e propriedade privada: Direitos territoriais quilombolas no Brasil. Dissertação de Mestrado: Programa de Pós-Graduação em Direito da Universidade Federal do Paraná, 2011.

MINISTÉRIO PÚBLICO DO RIO GRANDE DO SUL. Apud. RIO GRANDE DO SUL. Tribunal de Justiça do Rio Grande do Sul. Agravo de Instrumento no 70062538723. Relator: Desembargador L.P.P. Julgado em 28 de maio de 2015.

OST, François. Quelle jurisprudence pour quellesocieté? Archives de philosophie du droit. Tome 30. la jurisprudence - publié avec le concours du C.N.R.S. Paris, France: Sirey, 1985.

PARÁ. Tribunal de Justiça do Pará. Agravo de Instrumento no 0095731-37.2015.8.14.0000. Relator: Desembargador J.M.T.R. Julgado em 2015.

Tribunal de Justiça do Pará. Pedido de Suspensão de Medida Liminar no 000775407.2015.814.0000. Relator: Desembargador C.A.F. Julgado em 2015.

RIO GRANDE DO SUL. Tribunal de Justiça do Estado do Rio Grande do Sul. Agravo de Instrumento no70067772954. Relator: Desembargador G.R.S. Julgado em 14 de dezembro de 2015.

Tribunal de Justiça do Rio Grande do Sul. Agravo de Instrumento no 70067813790. Relator: Desembargador J.M.P. Julgado em 15 de dezembro de 2015.

Tribunal de Justiça do Rio Grande do Sul. Agravo Interno $n^{\circ}$ 70062200100. Relator: Desembargador N.J.G. Julgado em 20 de novembro de 2014.

Tribunal de Justiça do Estado do Rio Grande do Sul. Apelação Cível n 70059976944. Relator: Desembargador P.C.D.P. Julgado em 20 de novembro de 2014.

SANTILLI, Juliana. Socioambientalismo e novos direitos: proteção jurídica à diversidade biológica e cultural. São Paulo: Peirópolis, 2005.

SANTOS, Milton. Território e Sociedade - entrevista com Milton Santos. 2a ed. 4a reimpressão. São Paulo: Editora Fundação Perseu Abramo, 2009.

SÃO PAULO. Tribunal de Justiça de São Paulo. Agravo de Instrumento na 214103759.2015.8.26.0000. Relator: T.C. Julgado em 10 de dezembro de 2015.

Tribunal de Justiça do Estado de São Paulo. Agravo de Instrumento n. 20150000707461. Relator: M.C. Declaração de voto: L.S.F.S. Julgado em 21 de setembro de 2015.

Tribunal de Justiça de São Paulo. Apelação Cível no 0001033-06.2004.8.26.0642. Relator: F.L. Julgado em 15 de outubro de 2015. 
SARLET, Ingo Wolfgang. A eficácia dos direitos fundamentais: uma teoria geral dos direitos fundamentais na perspectiva constitucional. 12. ed. rev, atual e ampl. Porto Alegre: Livraria do Advogado Editora, 2015.

O Direito Fundamental à Moradia na Constituição: Algumas Anotações a Respeito de seu Contexto, Conteúdo e Possível Eficácia. Revista Eletrônica sobre a Reforma do Estado (RERE), Salvador, Instituto Brasileiro de Direito Público, n² 20, dezembro, janeiro, fevereiro, 2009, 2010, p. 33. Disponível em: <http://www.direitodoestado.com/revista/rere-20-dezembro-2009-ingosarlet.pdf>. Acesso em 23 de outubro de 2015.

Trabalho enviado em 11 de julho de 2017.

Aceito em 20 de outubro de 2017. 